\title{
RECENZIJA
}

\section{KAKO NAJ POTEKAJO VOJNE? \\ VOJAŠKA STRATEGIJA V PRIMERJAVI \\ S POLITIČNIMI ODLOČITVAMI}

Vsakega bralca, ki kupi najnovejšo knjigo Why America Loses Wars: Limited War and US Strategy from the Korean War to the Present (Zakaj Amerika izgublja vojne - omejena vojna in ameriška strategija od korejske vojne do danes) (Cambridge: Cambridge University Press, 2019) profesorja Donalda Stokerja ${ }^{1}$, v kateri avtor analizira vojne in spopade Združenih držav Amerike od korejske vojne naprej, čaka zanimivo branje. Zaradi provokativnega naslova knjige jo bralec začne brati z rahlim nezaupanjem, saj je ta v nasprotju s podobo ZDA kot vodilne svetovne sile, ki lahko skoraj vse države sveta prepriča v sodelovanje z njo bodisi v političnem, gospodarskem ali vojaškem smislu. Zelo pretresljivo je zato spoznanje, kako različno voditelji ameriških in zahodnih držav razmišljajo o vojni. V številnih primerih ne vedo natančno, kaj vojna sploh pomeni in kakšne so lahko posledice njenega izbruha in spopadov. V več spopadih se je izkazalo, da so v tej vodilni svetovni velesili politični odločevalci v neki situaciji razmišljali povsem drugače, kar je pogosto pripeljalo do nasprotujočih si odločitev. Glavni razlog za to ni politična pripadnost, temveč dejstvo, da politiki in vojaki, ki sodelujejo v spopadih, nimajo enake predstave

\footnotetext{
Donald Stoker je bil profesor strategije in politike v programu ameriške vojaške šole US Naval War College na Naval Postgraduate School v Montereyu v Kaliforniji od leta 1999 do 2017. Je avtor ali urednik 11 knjig, njegova knjiga Carl von Clausewitz: His Life and Work (Carl von Clausewitz: življenje in delo) (Oxford University Press, 2014) je na seznamu obveznega strokovnega čtiva britanske kopenske vojske. Njegova knjiga The Grand Design: Strategy and the US Civil War, 1861-1865 (Oxford University Press, 2010) je prejela prestižno nagrado Fletcher Pratt, vključena je bila v glavni izbor knjig knjižnega kluba History Book Club, je na seznamu obveznega čtiva načelnika štaba ameriške kopenske vojske in se pogosto uporablja kot študijsko besedilo na tečajih strateških študij in zgodovine v ZDA in drugod. Leta 2016 je bil Stoker strokovni sodelavec v programu Changing Character of War Programme na Pembroke Collegeu univerze v Oxfordu. Vštudijskem letu 2017-2018 je bil zaslužni profesor političnih znanosti programa Fullbright na diplomatski akademiji na Dunaju v Avstriji. Trenutno je višji strokovni sodelavec pri organizaciji Atlas v Washingtonu in piše knjigo American Grand Strategy, 1775-2020 (Ameriška velika strategija, 1775-2020) za založbo Basic Books. Njegova najnovejša knjiga je Why America Loses Wars: Limited War and US Strategy From the Korean War to the Present (Zakaj Amerika izgublja vojne - omejena vojna in ameriška strategija od korejske vojne do danes) (Cambridge University Press, 2019). Živi v Montereyu v Kaliforniji.
} 
glede ciljev in rezultatov, ki bi jih bilo treba doseči, ali strategij, ki bi jih bilo treba uporabiti. V številnih primerih je to pripeljalo do nepotrebnih izgub in vojn, ki so trajale veliko dlje, kot bi bilo potrebno. Tak primer sta Irak in Afganistan.

Oblikovalci politik se pogosto ne zavedajo stare modrosti Carla von Clausewitza, ki ga Stoker pogosto citira in izhaja iz njegove knjige $\mathrm{O}$ vojni, da je vojna nadaljevanje politike z drugimi sredstvi. Ta izjava predpostavlja, da politiki začnejo spopad z jasnimi cilji in natančno predstavo o tem, katere rezultate želijo doseči. Poleg tega se zavedajo, da lahko na uspeh vojne, pa naj bo še tako kratka ali omejena, vplivajo dejavniki, kot so geografsko okolje, gospodarsko ozadje, logistične zmogljivosti, socialna podpora, zgodovinsko in kulturno ozadje ter drugo. Vendar se lahko nekateri od teh dejavnikov med spopadom spremenijo, zato je treba cilje in strategije občasno pregledati in jih, če je treba, preoblikovati glede na trenutno realno stanje.

Jordan Ellenberg je o teh starih resnicah podobno razmišljal v svoji knjigi How Not to Be Wrong: The Power of Mathematical Thinking (Kako ne biti v zmoti: moč matematičnega razmišljanja), v kateri je zapisal, da države v vojnah ne zmagajo le zato, ker so pogumnejše ali svobodnejše od nasprotne strani ali ker jih ima Bog nekoliko raje. Zmagovalci so navadno fantje, ki jim sestrelijo za približno 5 odstotkov manj letal, ki porabijo 5 odstotkov manj goriva ali za svojo pehoto dobijo 5 odstotkov več hrane za 95 odstotkov stroškov. To niso stvari, ki bi bile del vojnih filmov, so pa stvari, ki so del vojne. In matematika je prisotna na vsakem koraku. ${ }^{2}$ Kljub temu večina političnih odločevalcev, ki svoje države vodijo v neskončne vojne, na te stvari nenehno pozablja. Posledice teh vojn trpijo vojaki, ki se borijo v bitkah, in civilno prebivalstvo na prizadetih območjih. Stoker torej na te odločevalce upravičeno prenaša krivdo za neustrezno uporabo strateškega razmišljanja. To je še posebno pomembno glede na dejstvo, da se obdobje »omejene vojne«, ki je zaznamovalo zadnji dve desetletji, končuje, in kaj lahko se zgodi, da se bo ZDA soočila z vse bolj enakovrednimi nasprotniki, kot sta Kitajska in Rusija. Pričakovati je, da bo šlo za konvencionalen spopad, na kar pa ameriška politična in vojaška vodstvena struktura, vajena protiuporniškega delovanja in hitrih uspehov, verjetno ne bo ustrezno pripravljena. S tega stališča bi lahko ta knjiga delovala celo kot opozorilo voditeljem, naj se začnejo pripravljati na poznejše obdobje, čeprav avtor ne predlaga načinov, kako to, kar je zapisal, uporabiti v praksi.

Ena glavnih odlik knjige je, da pojasnjuje pogosto uporabljene politične in vojaške koncepte, kot so enostranskost, večstranskost, vrste političnih ciljev, strategija, taktika, cilji, operacije, vnaprejšnja in preventivna vojna, vojna v sivem območju, omejena vojna, mala vojna, ugnezdena vojna, zmaga in mir. Druga resna dodana vrednost knjige je, da skoraj fanatično poudarja potrebo po aktivnejšem,

\footnotetext{
Jordan Ellenberg: How Not to Be Wrong: The Power of Mathematical Thinking, Penguin, 2014, str. 7 ("Countries don't win wars just being braver than the other side, or freer, or slightly preferred by God. The winners are usually the guys who get $5 \%$ fewer of their planes shot down, or use $5 \%$ less fuel, or get $5 \%$ more nutrition into their infantry at $95 \%$ of the cost. That's not the stuff war movies are made of, but it's the stuff wars are made of. And there's math every step of the way.")
} 
učinkovitejšem dialogu in sodelovanju med politično in vojaško stranjo, zaradi česar se lahko težave pri razlagi med različnimi skupinami in akterji znatno zmanjšajo in sodelovanje izboljša. Predvsem se mi je zdelo zanimivo, da je avtor predstavil več političnih in vojaških dogodkov, ne samo iz ameriškega, temveč tudi mednarodnega okolja, več postopkov odločanja, ki do njih privedejo, ter njihovo ozadje, ki ga veliko zgodovinarjev in vojaških zgodovinarjev ne pozna v celoti. Avtor poleg opisa zgodovinskih dogodkov omenja tudi številne vojaške in politične stratege, kot so Sun $\mathrm{Cu}$, Carl von Clausewitz, Bernard Brodie (bolj znan v ZDA) in drugi, ter njihova razmišljanja, ki na neki način še danes vplivajo na vojskovanje, čeprav se z nekaterimi ne strinja. Kljub vsemu sem poleg številnih pozitivnih strani knjige pogrešal dejstvo, da avtor, čeprav predstavi skoraj vsak ameriški konflikt v zadnjih nekaj desetletjih, govori le o tem, da se ZDA »zapletajo v neskončne vojne«, in ne o tem, kako je vojna večkrat tudi dosegla svoj cilj, na primer v Grenadi, Panami ali na Balkanu. Morda bi veljalo natančneje pogledati, čemu te uspehe pripisati, in iz tega kaj ugotoviti. Kljub vsemu pa to ne vpliva na vrednost knjige.

Še posebej mi je bilo všeč, da je Stoker ostal zvest svojim preteklim izkušnjam predavatelja na univerzi in je knjigo oblikoval tako, da lahko koristi tudi tistim, ki to področje manj poznajo. K temu pripomorejo jasne razlage in obsežne razprave o različnih konceptih. Bralci iz različnih okolij tako dobijo enotno predstavo o tem, kako poteka politično odločanje, kaj je vojna, kako se v njej boriti in, kar je najpomembnejše, kako jo končati, kaj različni akterji o njej mislijo, predstavi pa tudi razlike v načinih razmišljanja politikov in vojakov, ki v vojni sodelujejo. Po drugi strani bi lahko bila knjiga zelo koristna tudi za politične in strateške odločevalce. Ti pogosto z minimalnim znanjem in pomanjkanjem ustreznih osnovnih informacij sprejemajo odločitve, ki lahko imajo zelo resne posledice. Kot veteran z 31-letnimi izkušnjami v poklicni vojski, ki je kariero začel s činom vodnika v bojni enoti in končal kot polkovnik na generalštabu, se popolnoma strinjam z avtorjevo knjigo, ki bi jo morali prebrati ne samo ameriški, temveč tudi politični in vojaški voditelji vseh drugih držav kot nekakšno gradivo osnovnega strateškega šolanja in se tako naučiti, kako sprejemati premišljene odločitve o vojaških vprašanjih, kako uspešno in razumljivo posredovati med političnimi odločitvami in vojaškimi skupnostmi, ki jih izvajajo, in kakšne so lahko posledice odločitev, ki jih sprejemajo. 